\title{
Anaemia and iron deficiency in female players in Albania; comparison with a reference group
}

\author{
DHURATA BOZO \\ Sport University of Tirana, Research Institute of Sport Science. Tirana, Albania
}

\begin{abstract}
Bozo, D. (2014). Anaemia and iron deficiency in female players in Albania; comparison with a reference group. J. Hum. Sport Exerc., 9(Proc1), pp.S460-S466. Alterations of the red blood cell system and iron metabolism can influence physical performance. On the other hand, exercise can influence haematological variables (Petibois et al., 2003). Screening for anaemia in sports persons is carried out primarily for health concern and secondly because it contributes to morbidity and diminished exercise performance (Descorges, 2008). While several studies in endurance sports show that dilutional "sports anaemia" can occur in the more elite athlete as an adaptation to aerobic conditioning, the prevalence of iron deficiency and its impact on performance have not been adequately investigated in non-endurance athletes (Di Santolo et al., 2008). The main objective of this study is to investigate the red blood cell population markers and the iron status in a group of 52 female volleyball players, and to identify possible differences with subjects of a reference sedentary group and the underlying factors underlying such responses. Eleven blood markers, of the red and white cell populations and the serum iron were studied in 52 female volleyball players from the local and university teams and 47 referent subjects, all aged 18-26 years, in blood samples taken from the cubital vein under standard conditions. The blood variables were analysed with an automatic cell counter, while iron status with a UV/visible spectrophotometer. Both female players and reference groups show similar range values for most of the blood markers and no significant differences $(p<0.05)$ in means values for most of them. Players tend to have lower haemoglobin concentrations (35\% of the subjects, under the norm vs $22 \%$ of the referents), RBC counts (32\% under the normvs $20 \%$ ), haematocrit level( $35 \%$ under the normvs $22 \%$ ) than sedentary counterparts. Iron status (only $12 \%$ under the norm for the players against $10.5 \%$ in referent subjects), differently from the RBC and $\mathrm{Hgb}$ data, demonstrate that iron deficiency does not seem to be the main and the only underlying factor for anaemia in the players groups. This is confirmed also by the differences in MCH, MCV and MCHC values between the two groups, which follow and are colinear to iron status data and intergroup differences. These data show that female players are in the borderline of the iron-dependent anaemic state, but with no significant differences with the referent counterparts, thus supporting the idea from other authors that, non-endurance physical activity, does not adversely affect particularly the iron stores (Di Santolo et al., 2008), (Schumacher, et al, 2002). The significant differences between the groups for other blood indices like RBC counts, haematocrit, Hgb and others seems more likely to be due to the response to training volume, method and periodicity (Withold et al., 2011). Key words: FEMALE VOLLEYBALL, BLOOD MARKERS, IRON STATUS, NON-ENDURANCE RESPONSE.
\end{abstract}

Corresponding author. Sport University of Tirana, Research Institute of Sport Science. Tirana, Albania.

E-mail: dhuratabozo@gmail.com

8th INSHS International Christmas Sport Scientific Conference, 5-7 December 2013. International Network of Sport and Health Science. Szombathely, Hungary.

JOURNAL OF HUMAN SPORT \& EXERCISE ISSN 1988-5202

(c) Faculty of Education. University of Alicante

doi:10.14198/jhse.2014.9.Proc1.33 


\section{INTRODUCTION}

Iron is an essential trace element, constituent of haemoglobin, myoglobin and cellular enzymes involved in the energy productions in the cells. It is therefore important for many body functions, having a direct and indirect impact on the physiological and metabolic processes dealing with physical and sport activity. Therefore body iron deficiency has debilitating effects on athletic performance as a result of reduced aerobic work capacity and impaired cognition (Radjen et al., 2011; Milic, 2011; Raunikar \& Sabio, 1992; Schumacher et al., 2002).

Iron deficiency (ID) is a nutritional common problem reported both in the population and athletes undergoing heavy and/or improper training. It affects almost $50 \%$ of the population worldwide, making it the most common mineral deficiency of all. Iron deficiency anemia (IDA) is the end state of ID. Different studies show that there is a clear and significant gender difference, with ID being prevalent mostly among women (Di Santolo et al., 2008; Mercer \& Densmore, 2005).

When approaching and investigating on iron dependent anemia it is important to distinguish between sport/dilutional anemia (SA) and the true Iron deficiency anemia (IDA) (Deakin, 1995; Zimmermann \& Hurrell, 2007; Milman, 2011).

Sport anemia, described as more common in sportpersons, is not considered a true iron deficiency. It is characterized by blood and iron status measures such as serum iron, haematocrit and haemoglobin that are lower than usual reference standards. Regular physical training leads to an increase in plasma volume by $10-20 \%$. Therefore $\mathrm{Hb}$ concentration slightly below normal values in the presence of low-normal Fe blood in athletes are mainly due to a "dilutional anemia" or the socalled "pseudoanemia". Several prior studies indicate that true iron deficiency anemia is not more frequent in athletes than in the general population. Since regular, especially extensive, physical activity increases iron loss, mild iron deficiency (abnormal Fe deficiency but normal $\mathrm{Hb}$ concentration) mat establish. Sometimes true Fe deficiency anemia can occur especially when nutritional intake of $\mathrm{Fe}$ is insufficient and/or iron loss is excessive (ex. menstruation in young women). Therefore young athletes, especially females, are more exposed to this kind of Fe dependent anemia (Beals, 2002; Bartsch et al., 1998; Risser et al., 1988; Landahl et al., 2005).

The "dilutional sport anemia" (DSA) that occurs in young athletes may result as an adaptation to aerobic conditioning. This adaptive response is more or less marked depending on the type, time and length of training programs, as well as the adequacy and appropriateness of such for different athletes. The changes in blood indices are higher in the initial phase of a restored or of a new training program. Therefore, screening for anemia in young-aged, especially female athletes is particularly important, not only as a health concern but also cause it may contribute to morbidity, diminished physical performance ad decrease in efficiency of the physiological adapting and responding mechanisms to training. Sports anemia therefore is not considered a true iron deficiency anemia in that iron is not the limiting factor for red blood cell production and restore. Actually this is a usually transitory and is resistant to iron supplements (Radjen et al., 2011; Milic, 2011; Raunikar \& Sabio, 1992).

Iron deficiency anemia (IDA) is similarly characterized by low $\mathrm{Hb}$, low HCT and low iron status, but differs from sport anemia in that there is insufficient iron available for the production of $\mathrm{Hb}$ in the red blood cells. The onset and disappearing of this anemia is collinear to iron depletion and supplement, being thus a true iron dependent anemia. Unlike sport anemia this condition improves by increasing the iron supply in the diet or by using iron supplements (Schumacher et al., 2002; Milman, 2011). 
Interpretation of low values for iron status as indicative of true iron deficiency anemia is ambiguous. For some athletes low values may be due to a physiological adaptation to exercise and therefore not representative of true iron deficiency anemia. Reduced levels may represent a dilutional effect associated with increase in plasma volume (dilutional anemia), and decrease of Hgb concentration, RBC count, serum iron and other dependent indices. However these low values are observed in athletes at the start or restart of a training program and are rarely decrease performance capacity (Schumacher et al., 2002; Sandstrom et al., 2012; Shaskey \& Green, 2000; Ferrari et al., 2011).

As it is not always easy to differentiate between sports anemia and iron deficiency anemia in the early stages and especially in young females, it is prudent therefore to investigate, monitor and treat all low iron stata as potential iron deficiency conditions (Di Santolo et al., 2008; Sandstrom et al., 2012; Ferrari et al., 2011; Hoppem et al., 2008).

Despite the numerous studies carried out about the relation between ID and physical activity in female athletes, th e results are varying and controversial. Some report that team sport athletes have better iron status than controls, others reported no difference, while other studies showed that athletes are more iron depleted than nonathlete women. However, it is still not clear if female athletes have a higher prevalence of ID and IDA than age-matched controls. Moreover, the prevalence of iron deficiency and its possible impact on physical and sport performance has not been adequately investigated in non endurance athletes such as in volleyball or other team sports players. (Milman, 2011; Dubnov \& Constantini, 2004; Nuviala et al., 1996; Beard \& Tobin, 2000; Malszewska et al., 2000).

The main goal of this study was to first screen for anemia among young female volleyball players and to identify possible differences in haematological status with a reference group of sedentary nonplayers counterparts, as well as understand the underlying factors of such differences if any. As iron deficiency in its health and performance effecting approach has not been previously investigated in non endurance athletets, this was a further aim of this research.

\section{MATERIALS AND METHODS}

Participants: A total of 99 healthy young female, 52 female volleyball players and 47 age-matched young women as a reference group, participated in this research. The female players belonged to both Albanian Junior and Elite volleyball teams. The mean age was around 21 years in both groups (range, 16-26 years in athletes and 17-27 years in nonathletes, respectively.

Measures and Procedures: Height and weight measures and BMl calculation were performed for both groups according to standard procedures and formulas. Body mass index (BMI) was calculated from the weight (in kilograms) divided by the square of the height (in meters). Blood markers of the red cell system and iron status were also determined. These markers included Red Blood Cells Count-RBC, Haemoglobin Concentration-Hgb, Haematocrit-Hct, Mean Corpuscular (erythrocyte) Volume-MCV, Mean Cell (erythrocyte) Hemoglobin-MCH, Mean Cell (erythrocyte) Hemoglobin Concentration-MCHC and serum iron.

Blood sampling took place in the morning, under standard conditions, with an empty stomach after an overnight fasting. The blood from the antecubital vein was collected in tubes containing K3EDTA. The concentration of hemoglobin $(\mathrm{Hb})$, the erythrocyte indices (MCV, $\mathrm{MCH}$, and $\mathrm{MCHC}$ ), and erythrocyte particular concentration was determined with an Automatic cell counter (Haemoanalyzer "Mindray BC- 
3000 Plus). Serum was separated and analysis of serum iron (Fe), was performed according to a standard laboratory procedure using a standard, kit-based spectrophotometric method.

Analysis. Standard descpritive statistical methods (Mean and Standard Deviation) were used for the direct measures. One way variance analysis for the comparison of data between the study and reference groups. A $5 \%$ probability level was determined as statistical significance of differences calculated for each parameter.

\section{RESULTS}

The physical body characteristics of the participants of both groups under investigation are presented in Table 1. The age was in average 21 years in both groups (range, 16-26 years in players and 17-27 years in nonplayers, respectively). There were not found significant difference nor in weight between the 2 study groups, with an average weight of $66 \pm 6.1 \mathrm{~kg}$ (range, $57-72 \mathrm{~kg}$ ) in players, compared with nonplayers, with an average weight of $66 \pm 5.5 \mathrm{~kg}$ (range, $59-73 \mathrm{~kg}$ ). There was no significant difference in height between the 2 groups, with an average height in the players $1.67 \pm 1.5 \mathrm{~m}$ (range, 1.6-1.8 $\mathrm{m}$ ) compared to the nonplayers with $1.65 \pm 1.9 \mathrm{~m}$ (range, 1.6-1.8 m). Similarly to height and weight, the calculated BMI showed no differences in mean values, being of $22.9 \pm 1.7 \mathrm{~kg} / \mathrm{m} 2$ (range, $19-24 \mathrm{~kg} / \mathrm{m} 2$ ) in female players and 23.7 $\pm 2.1 \mathrm{~kg} / \mathrm{m} 2$ (range, $20-24 \mathrm{~kg} / \mathrm{m} 2$ ) in nonplayers.

Table 1. Body characteristics of the groups under investigation

\begin{tabular}{l|l|l|l|l}
\hline Characteristics & \multicolumn{2}{c}{$\begin{array}{c}\text { Volleyball players } \\
\mathrm{N}=52\end{array}$} & \multicolumn{1}{c}{$\begin{array}{c}\text { Reference group } \\
\mathrm{N}=47\end{array}$} \\
\cline { 2 - 5 } & \multicolumn{1}{c}{ Average \pm SD } & Range & Average + SD & Range \\
\hline & & $16-26$ & $21.6 \pm 3.9$ & $17-27$ \\
Age in years & $20.7 \pm 3.3$ & $57-72$ & $66 \pm 5.5$ & $59-73$ \\
Weight in $\mathrm{kg}$ & $66 \pm 6$ & $1.6-1.8$ & $1.65 \pm 1.9$ & $1.6-1.8$ \\
Height in m & $1.67 \pm 1.5$ & $19-24$ & $23.7 \pm 2.1$ & $20-24$ \\
BMI in $\mathrm{kg} / \mathrm{m}^{2}$ & $22.9 \pm 1.7$ & & & \\
& & & & \\
\hline
\end{tabular}

Figures and data related to red cell measures and iron status of the groups under investigation are shown in Table 2. As it can be seen, no significant differences were found for most of the red cell markers between the groups, both in terms of group interval as well as for groups markers averages. Two markers who show significant differences between groups where RBC (erythrocyte counts) have mean values of $4.14 \pm 3.9$ and $4.8 \pm 2.4 \times 1012$, in players and nonplayers respectively and Hct (haematocrit-red cell volume), with group average values of $33.7 \pm 4.1$ and $41.1 \pm 2.6 \%$ respectively. There were found no differences in $\mathrm{Hgb}$, $\mathrm{MCV}, \mathrm{MCH}$ and $\mathrm{MCHC}$ between the players and group taken as reference. Unexpectedly, we found no significant difference between the 2 groups in serum iron, being $65 \pm 3.1 \mu \mathrm{d} / \mathrm{dL}$ in the study group and $70 \pm$ $2.9 \mu \mathrm{d} / \mathrm{dL}$ in the reference group. 
Table 2. Red blood measures and iron status of the groups under investigation

\begin{tabular}{|c|c|c|c|c|c|}
\hline \multirow[t]{2}{*}{ Markers } & \multicolumn{2}{|c|}{$\begin{array}{l}\text { Volleyball players } \\
\quad \mathrm{N}=52\end{array}$} & \multicolumn{2}{|c|}{$\begin{array}{l}\text { Reference group } \\
\qquad \mathrm{N}=47\end{array}$} & \multirow[t]{2}{*}{$\begin{array}{c}\text { Normal } \\
\text { value range }\end{array}$} \\
\hline & Average \pm SD & Range & Average \pm SD & Range & \\
\hline $\mathrm{RBC} \times 10^{12}$ & $4.14 \pm 8.9$ & $8.88-5.14$ & $4.8 \pm 2.4$ & $8.7-5.4$ & $4.2-5.4$ \\
\hline Het $\%$ & $88.7 \pm 4.1$ & $29.2-40.7$ & $41.1 \pm 2.6$ & $29-47.8$ & $86.1-44.8$ \\
\hline $\mathrm{Hb} \mathrm{g} / \mathrm{L}$ & $11.8 \pm 8.1$ & $8.6-14.8$ & $12.6 \pm 2.0$ & $9.2-15.6$ & $12.1-15$ \\
\hline $\mathrm{MCV}$ fL & $65.9 \pm 8.7$ & $68.7-98.1$ & $66.2 \pm 2.8$ & $78-92.8$ & $80-99$ \\
\hline $\mathrm{MCH} \mathrm{pg}$ & $21.6 \pm 1.6$ & $20.01-88.1$ & $24.8 \pm 2.8$ & $28-80.9$ & $27.5-88.5$ \\
\hline $\mathrm{MCHC}$ g $\mathrm{L}$ & $81.8 \pm 2.2$ & $29.4-85.2$ & $88.1 \pm 1.2$ & $81.6-84.2$ & $82-86$ \\
\hline $\mathrm{Fe} \mu \mathrm{g} / \mathrm{dL}$ & $65 \pm 8.1$ & $58-168$ & $70 \pm 2.9$ & $58-165$ & $60-170$ \\
\hline
\end{tabular}

Table 3. Anemia status markers: erythrocyte measures and iron status under normal values of the groups under investigation

\begin{tabular}{|c|c|c|c|c|}
\hline \multirow[t]{2}{*}{ Markers } & \multicolumn{2}{|c|}{$\begin{array}{c}\text { Volleyball players } \\
\mathrm{N}=52\end{array}$} & \multicolumn{2}{|c|}{$\begin{array}{l}\text { Reference group } \\
\qquad \mathrm{N}=47\end{array}$} \\
\hline & $\mathrm{N}$ under $\mathrm{NV}^{*}$ & $\%$ & N under NV & $\%$ \\
\hline $\mathrm{RBC} \times 10^{39}$ & 14 & 27 & 4 & 9 \\
\hline Het $\%$ & 15 & 29 & 10 & 22 \\
\hline $\mathrm{Hb} g / \mathrm{L}$ & 15 & 29 & 4 & 9 \\
\hline MCV fL & 5 & 10 & 8 & 7 \\
\hline $\mathrm{MCH} p g$ & 10 & 19 & 6 & 18 \\
\hline $\mathrm{MCHC}_{\mathrm{g}} \mathrm{L}$ & 5 & 10 & 6 & 18 \\
\hline $\mathrm{Fe} \mu \mathrm{g} / \mathrm{dL}$ & 5 & 10 & 4 & 9 \\
\hline
\end{tabular}

${ }^{*} \mathrm{~N}$ under NV: number of individual showing measures below the normal values range

In Table 3 and Figure 1 are shown comparable data on iron anemia incidence in players and nonplayers groups, in percentage of individuals showing values below the normal value for each marker and measure under analysis.

In terms of individual figures, 14 of 52 players show low RBC against 4 of 47 of nonplayers (respectively 27 and $9 \%$ ), 15/52 of players and 10/47 of nonplayers have low Hct, 15/52 players and 4/47 nonplayers low $\mathrm{Hgb}$, with a slight tendence of players for lower $\mathrm{Hgb}$ concentration. For $\mathrm{MCV}, \mathrm{MCH}, \mathrm{MCHC}$ and serum iron the incidence of individuals showing abnormal data is alike. The majority of individuals with lower erythrocyte indices do not present an iron deficiency, or a marked iron deficiency. In total we found that only 5 of 15 , out of overall 52 players $(10 \%)$ and only 4 of 10 , out overall 47 nonplayers $(\approx 9 \%)$, with abnormal erythrocyte indices have an iron deficiency associated anemia; therefore the difference is not significant. Among the 5 players with anemia, 3 had certain IDA with low hemoglobin ( 86,96 and $98 \mathrm{~g} / \mathrm{L})$, and 2 had a borderline anemia, with their hemoglobin value between 10-12 g/L. In the reference group, 2 had certain IDA with low hemoglobin (92 and $99 \mathrm{~g} / \mathrm{L})$, and 2 had a borderline anemia. 


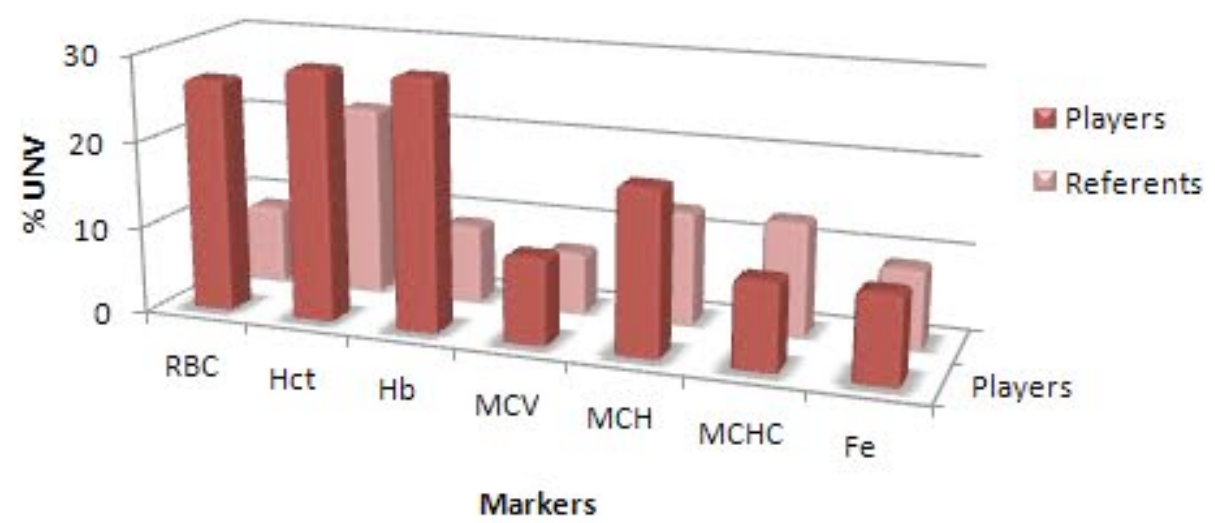

Figure 1. Comparison of anemia markers between groups

\section{DISCUSSION AND CONCLUSIONS}

Both female players and reference groups show similar range values for most of the blood markers and no significant differences $(p<0.05)$ in means values for most of them. Although players tend to have lower hemoglobin concentrations, RBC counts, haematocrit level than sedentary referent counterparts, serum iron data demonstrate that iron deficiency does not seem to be the main and the only underlying factor for anemia in the players groups. This is confirmed also by the differences in $\mathrm{MCH}, \mathrm{MCV}$ and MCHC values between the two groups, which follow and are associated to iron status data and intergroup differences, especially at individual level. These data show that female players are in the borderline of the irondependent anemic state, but with no significant differences with the referent counterparts, thus supporting the idea from other authors that, non-endurance physical activity, does not adversely affect particularly the iron stores. The significant differences between the groups for other blood indices like RBC counts, haematocrit, Hgb and others seem more likely to be due to a "dilutional or pseudoanemia" more than an iron deficiency consequence. These response may be also related the adequacy and/or appropriateness of the training program and of the individual and group response to training volume, method and periodicity (Di Santolo et al., 2008; Schumacher et al., 2002; Beard \& Tobin, 2000).

The above conclusions are particularly important for the trainers, who should consider and undertake continuous controls and monitoring of the athletes, especially in females, not only for health purposes, but also to evaluate and judge on the appropriateness and effectiveness of the training programs, especially when introducing new and untried or alternative ones.

\section{REFERENCES}

1. Bartsch, P., Mairbaurl, H. \& Friedman B. (1998). Pseudo-anemia caused by sports. Ther Umsch, 55(4), pp.251-5.

2. Beals, K.A. (2002). Eating behavior, nutritional status and menstrual function in elite female adolescent volleyball players. J Am Diet Assoc, 102(9), pp.1293-6.

3. Beard, J. \& Tobin, B. (2000). Iron status and exercise. Am J Clin Nutr, 72(2 suppl), pp.594S-597S. 
4. Deakin, V. (1995). Sports anemia and iron deficiency in athletes. Paper of the National Sports Research Center. Australian Sport Commission.

5. Di Santolo, M., Stel, G., Banfi, G., Gonano, F. \& Cauci, S. (2008). Anemia and iron status in young fertile non-professional female athletes. Eur J Appl Physiol, 102(6), pp.703-9.

6. Dubnov, G. \& Constantini, N.W. (2004). Prevalence of iron depletion and anemia in top-level basketball players. Int J Sport Nutr Exerc Metab, 14, pp.30-37.

7. Ferrari, M., Mistura, L., Patterson, E. et al. (2011). Evaluation of iron status in European adolescents through biochemical iron indicators: the HELENA Study. Eur J Clin Nutr., 65, pp.340349.

8. Hoppe, M., Sjöberg, A., Hallberg, L., et al. (2008). Iron status in Swedish teenage girls: impact of low dietary iron bioavailability. Nutrition, 24, pp.638-645.

9. Landahl, G., Adolfsson, P., Borjesson, M. et al. (2005). Iron deficiency and anemia: a common problem in female elite soccer players. Int J Sport Nutr Exerc Metab, 15, pp.689-694.

10. Malczewska, J., Raczynski, G. \& Stupnicki, R. Iron status in female endurance athletes and in nonathletes. Int J Sport Nutr Exerc Metab, 10, pp.260-276.

11. Mercer, K.W., Densmore, J.J. (2005). Hematologic disorders in the athlete. Clin Sports Med, 24, pp.599-621, ix.

12. Milic, R. \& Dopsaj, M. (2011). Possible differences in hematological status between junior and elite female volleyball players. Br J Sports Med, 45, pp.539.

13. Milman, N. (2011). Anemia—still a major health problem in many parts of the world! Ann Hematol, 90, pp.369-377.

14. Nuviala, R.J., Castillo, M.C., Lapieza, M.G., et al. (1996). Iron nutritional status in female karatekas, handball and basketball players, and runners. Physiol Behav, 59, pp.449-453.

15. Radjen, S., Radjen, G., Zivotic-Vanovic, M., Radakovic, S., Vasiljevic, N. \& Stojanovic D. (2011). Effect of iron supplementation on maximal oxygen uptake in female athletes. Vojnosanit Pregl, 68(2), pp.130-5.

16. Raunikar, R.A. \& Sabio, H. (1992). Anemia in the adolescent athlete. Am J Dis Child, 146(10), pp.1201-5.

17. Risser, W.L., Lee, E.J., Poindexter, H.B., West, M.S., Pivarnik, J.M., Risser, J.M. \& Hickson, J.F. (1988). Iron deficiency in female athletes: its prevalence and impact on performance. Med Sci Sports Exerc, 20(2), pp.116-21.

18. Sandström, G., Börjesson, M. \& Rödjer, S. (2012). Iron Deficiency in Adolescent Female AthletesIs Iron Status Affected by Regular Sporting Activity? Clin J Sport Med, 22(6), pp.495-500.

19. Schumacher, Y.O., Schmid, A., Grathwohl, D., Bultermann, D. \& Berg, A. (2000). Hematological indices and iron status in athletes of various sports and performances. Med Sci Sports Exerc, 34(5), pp.869-75.

20. Shaskey DJ, Green GA. Sports haematology. Sports Med, 29, pp.27-38.

21. Zimmermann, M.B. \& Hurrell, R.F. (2007). Nutritional iron deficiency. Lancet, 370, pp.511-520. 